\title{
Influence of phase change within a 90-year-old Sequoia sempervirens on its in vitro organogenic capacity and protein patterns
}

\author{
Marie-Claude Bon*, Frédérique Riccardi, Olivier Monteuuis* \\ AFOCEL, Station de Biotechnologies, Domaine de l'Etançon, F-77370 Nangis, France
}

\begin{abstract}
Shoot-tips collected from stump shoots at the base of a 90-year-old Sequoia sempervirens and from the crown of the same donor tree were compared in respect of their organogenic performance in in vitro conditions. The cultures derived from stump shoots appeared to be much more responsive in terms of growth increment and adventitious rooting capacity - rooting rate, root length, average number of neoformed roots and root score - than cultures derived from the crown, although considerable variation was observed in all the organogenic criteria examined. The persisting topophysical differences in potential for in vitro organogenic and associated morphological traits characteristic of phase change were found to be connected with quantitative modifications of protein content. Thus, 23 membrane-associated proteins with molecular weights ranging from 22 to $58 \mathrm{kDa}$ appeared to be synthesized in greater abundance in the culture originating from the stump shoots.
\end{abstract}

Key words: Phase change - Protein - Sequoia sempervirens - Tissue culture - Topophysical influence

\section{Introduction}

The ontogenetic development of woody plants from the juvenile to the mature phase is associated with a number of changes, as reflected by modification of morphology, such as leaf form, or the attainment of the flowering state (Franclet 1985; Hackett 1985). This general phenomenon

* Present address: CIRAD-FORET / YAYASAN SABAH, P. O. Box 60793, 91017 Tawau, Sabah, Malaysia

Correspondence to: $\mathrm{O}$. Monteuuis has been referred to as "ontogenetical ageing" by Fortanier and Jonkers (1976), or as "phase change", which remains the most frequently used terminology (Brink 1962; Hackett 1983, 1985; Wareing 1987).

In arborescent species, it has been stated (Bonga 1982) that the basal parts close to the root system exhibit more juvenile characteristics than upper parts, which are chronologically younger, but appear older from the "ontogenetical ageing" point of view (Hackett 1985). Such a gradient of increasing maturity from the bottom to the top of the tree (Fortanier and Jonkers 1976) is clearly demonstrated in species capable of sprouting from the base of the trunk, where the stump shoots exhibit juvenile features that contrast with the mature characteristics of the shoots located in the crown (Franclet 1985).

The impact of phase change on intraclonal variability has been extensively reported (Hackett 1983), mostly from the standpoint of the negative effects of maturation on physiological abilities for true-to-type cloning, as manifested by difficulties for adventitious rooting or plagiotropic growth habit of the shoots (Hackett 1985). However, so far little is known about the basic origin of such manifestations.

Among the various endogenous compounds susceptible to such investigation, proteins have been the subject of special attention, with studies of their quantitative and qualitative differences in relation to maturity in several species (Fukasawa 1966; Bon 1988 a; Bon and Monteuuis 1991; Snowball et al. 1991; Huang et al. 1992). Particular reference has been made to the $16 \mathrm{kDa}$ membrane-associated protein called "J16", which characterized juvenility and connected cloning ability in Sequoiadendron giganteum (Bon 1988b). This incited us to concentrate on polypeptides for investigating the phenomenon of phase change and its consequences in terms of organogenic capacity with regard to the location of the shoots within a 90year-old Sequoia sempervirens (D. Don) Endl. This species was selected since: (1) it produces stump shoots; (2) phase change can be easily characterized by salient morphological markers (Franclet 1985); and (3) it is one of the few conifers to react well to in vitro culture conditions. 


\section{Materials and methods}

\section{Shoot origins}

The $S$. sempervirens from which the shoots were removed was 90 years old, about $30 \mathrm{~m}$ in height, and growing at the Arboretum National des Barres, Nogent-sur-Vernisson, France. The shoots consisted of the terminal parts of $0.2-0.8 \mathrm{~m}$ long stump shoots arising naturally from the base of the tree, and of shoots located $15 \mathrm{~m}$ higher in the crown.

\section{In vitro culture procedure}

Material from both origins was systematically paired during all the culture procedures. Cultures were initiated using $0.5 \mathrm{~cm}$ shoot-tips in accordance with Verschoore-Martouzet (1985). At the time of the experiments, the $2-\mathrm{cm}$-long microcuttings consisting of the upper part of the shoot with its terminal bud had been subcultured for 2 years at 2 -month intervals exclusively on the elongation medium (EM) that derived from a half-strength Murashige and Skoog (MS) medium supplemented with $20 \mathrm{~g} \mathrm{l}^{-1}$ activated charcoal (Boulay 1977; Fouret et al. 1986). The rooting procedure was described by Fouret et al. (1986): shoot-tips, $2 \mathrm{~cm}$ long, were induced for rhizogenesis for 1 week on a rooting induction medium (RIM) containing $5.10^{-5} \mathrm{M}$ NAA, then transferred for 6 weeks to the same medium without NAA, called rooting elongation medium (REM). All these media, except RIM, lacked growth regulators. The cultures were maintained under a $16 \mathrm{~h}$ photoperiod with a light intensity of $60-70 \mu \mathrm{Em}^{-2} \mathrm{~s}^{-1}$ provided by "Mazda-Fluor Lumière du Jour" fluorescent lamps, except for the rooting phase, which was carried out in darkness. Other experimental conditions were according to Fouret et al. (1986).

\section{Evaluation methods of organogenic potentiality}

Shoot growth was evaluated by measuring shoot increment at the end of the three successive 2-month subcultures on EM medium. Each sampling involved at least 50 individuals. Capacity for rhizogenesis was examined at the end of the 6 weeks on REM. Additionally to the proportion (\%) of rooted microcuttings, the following traits were recorded for each rooted explant: (1) total number of roots; (2) measurement of the longest root; (3) a root score, which permits the quantitative evaluation of the spatial distribution of the adventitiously neoformed roots. This last criterion was applied as defined by Struve and McKeand (1990): "dividing the cross-sectional area of each rooted microcutting base into quadrants, the longest root in quadrant 1 was assigned 1 point toward the root score; any additional roots in quadrant 1 were each assigned 0.25 points, whereas those in quadrants 2 or 4 were assigned 0.5 points and those in quadrant 3 were assigned 0.75 points". Rooting experiments were repeated 4 times. Each date $\times$ origin combination included 20-30 explants.

Using SAS software (SAS 1987), data were subjected to the $\chi^{2-}$ Pearson's test or the analysis of variance test ( $F$ test) to determine significant differences $(\boldsymbol{P}<0.05$ level of probability) among the experimental treatments.

\section{Biochemical assays}

Sample preparation and protein extraction. Protein analyses were carried out on elongating microcuttings on EM medium at the end of the two 2-month subcultures. Five hundred milligrams (fresh weight) of each material origin, corresponding to an average of 10 shoots, was extracted in the following cooled buffer: $100 \mathrm{mM}$ TRIS-HCl (pH 8.2), $1 \mathrm{mM} \mathrm{Na} 2$ EDTA, $2 \mathrm{mM} \mathrm{MgCl} 2,0.25 \mathrm{M}$ sucrose, $\beta$-mercaptoethanol $1 \%$ and $50 \mu \mathrm{g} \cdot \mathrm{ml}^{-1}$ phenylmethylsulphonyl fluoride (PMSF). The homogenate was then filtered through four layers of cheesecloth, centrifuged at $5000 \mathrm{~g}$ for $10 \mathrm{~min}$ and the resulting pellet discarded. The supernatant was centrifuged at $34000 \mathrm{~g}$ for $1 \mathrm{~h}$ to obtain a pellet, which was rinsed with TRIS buffer before being centrifuged at $34000 \mathrm{~g}$ for $1 \mathrm{~h}$. The resulting pellet was resuspended in TRIS buffer containing $0.5 \%$ deoxycholate, homogenized vigorously and stored at $4^{\circ} \mathrm{C}$ overnight. The homogenate was centrifuged at $34000 \mathrm{~g}$ for $1 \mathrm{~h}$ to yield a microsomal protein-enriched supernatant. Proteins of this fraction were quantified according to the method of Bradford (1976) using bovine serum albumin as the standard. This microsomal fraction was treated with cooled acetone and $\beta$-mercaptoethanol $0.07 \%$, dried under vacuum before the precipitated proteins were solubilized according to Granier and de Vienne (1986) in UKS buffer containing $9.3 \mathrm{M}$ urea, $5 \mathrm{mM} \mathrm{K}_{2} \mathrm{CO}_{3}, 0.5 \%$ SDS, $4 \%$ Triton X-100 and $5 \% \beta$-mercaptoethanol.

Gel electrophoresis. Two-dimensional separation of proteins was adapted from Bon (1989) with the following modifications: the dimensions of the glass tubes were $200 \mathrm{~mm}$ long and $1 \mathrm{~mm}$ internal diameter; the isoelectric focusing was carried out at $10000 \mathrm{~V} \times \mathrm{h}$, and the gels of the second dimension were run at a constant current of $30 \mathrm{~mA}$.

Proteins were stained with silver nitrate in accordance with Bon (1989) immediately after electrophoresis.

Four gels, two for each of two consecutive subcultures on EM, were analysed for each of the two material origins.

\section{Results}

\section{Capacity for organogenesis}

It appears from the three growth evaluations (Fig. 1 a) that the microcuttings from the basal part of the tree (stump shoots) exhibited higher growth increment than those from the crown $(55.6 \mathrm{~mm}$ vs $39.6 \mathrm{~mm}$ on average, $P<0.0001$ ). Growth performances in in vitro conditions were found to be greatly influenced by time course $(P<0.0001)$, with a strong origin $\times$ date interaction $(P<0.0001)$, as reflected by more or less pronounced differences between the two origins relative to the dates. Concurrently, original morphological features persisted, with much more developed leaves for the stump shoots than from the crown (Fig. 1f).

Referring to the ability for adventitious rooting, the basal part of the tree was overall more responsive than the crown in terms of rooted microcuttings ( $75 \%$ vs $19 \%$, $P<0.001)$, as well as when considering the average number of roots per rooted explant (3.6 vs 1.7, $P=0.006)$, the average measurement of the longest roots $(54.4 \mathrm{~mm}$ vs $42.3 \mathrm{~mm}, P=0.0151)$ and the average root score (2.3 vs $1.3, P=0.0003$ ). Whatever the trait examined, the scores for each origin were susceptible to great fluctuations related to the date of the experiment $(P<0.002)$, as illustrated in Fig. $1 b-e$.

\section{Protein patterns}

The two-dimensional patterns of the microsomal protein fraction showed that about 450 spots could be routinely resolved for each shoot origin (Fig. $2 a-b$ ), with quantitative differences in relative spot size and staining intensity. For the following results, our attention was focused on the spots scored as variable between the origins but unvaried during the time course. The spots which were susceptible to differ between the two dates of collection should be recorded in future experiments, where a greater number of subcultures are considered. 


\section{a SHOOT INCREMENT MEASUREMENT}

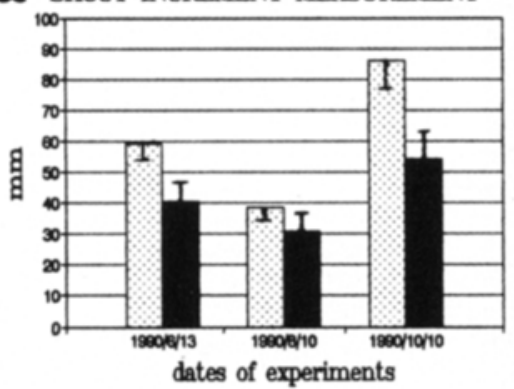

C

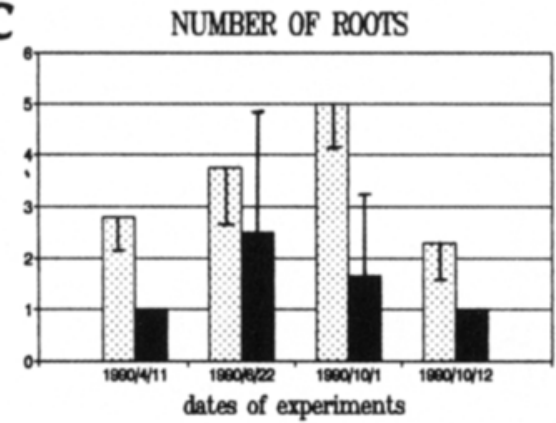

e

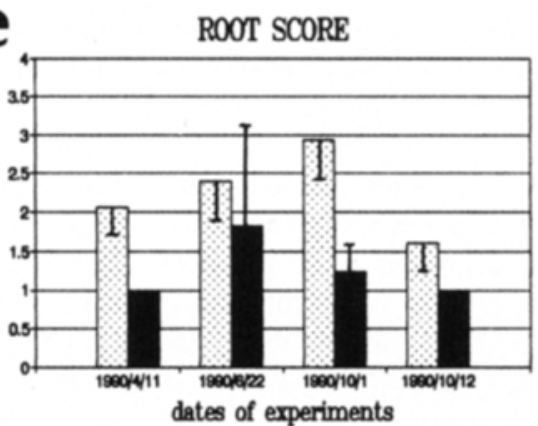

b

PERCENTAGE OF ROOTED EXPIANTS

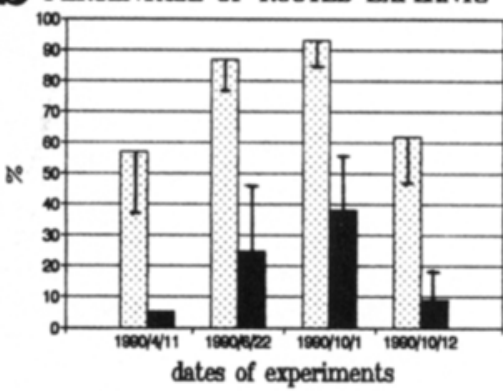

d

LONGEST ROOT MEASUREMENT

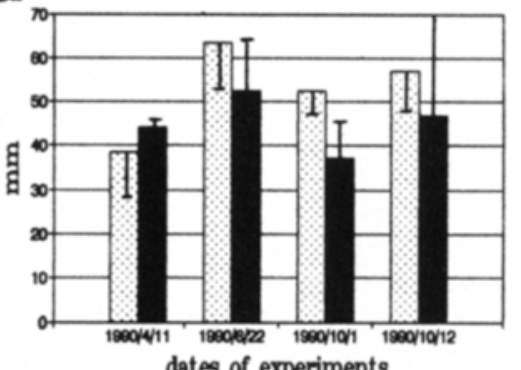

dates of experiments

f

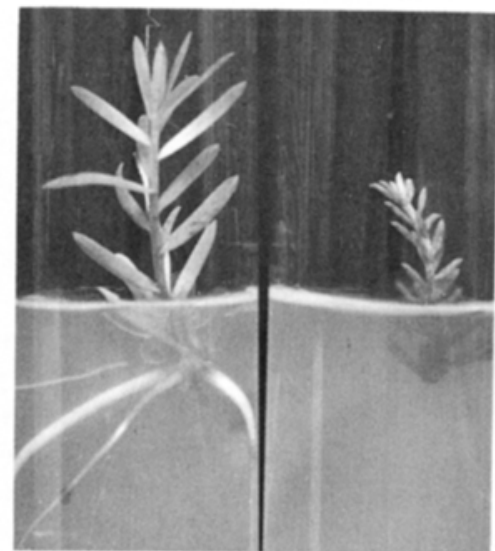

Fig. 1.a-e Comparative in vitro capacity average data for different organogenic traits of microcuttings from the base (중 and the crown ( of a 90-year-old Sequoia sempervirens; the two origins were systematically paired during all culture procedures. Vertical bars represent confidence intervals at $P=0.05$ level. $f$ Morphological differences between the base (left) and the crown (right) origins on the rooting expression medium $(x 1)$
Three clusters of spots appeared in greater quantity in basal shoot origin than in the crown one (Fig. 2 a). The first cluster was constituted of proteins of apparent 55-58000 molecular weight, approximately 33000 molecular weight for those composing the second cluster, and reduced to 22-24000 molecular weight for the third cluster. Proteins $1-5$ in the first cluster, $6-14$ in the second cluster and $15-23$ in the third cluster were detected at high relative rates in the stump shoot origin as compared to the crown one. Whatever the date of collection examined for the basal origin, a subset composed of polypeptides $2,3,15,16$, and $20-23$ seemed the most representative of the protein differences between the two origins (Fig. 2b). Our experiments did not reveal any qualitative difference in terms of the presence or absence of polypeptides between the samples collected from the stump or from the crown.

\section{Discussion}

The reported results attest the salient influence of the in situ location of the shoots within the donor tree on their subsequent potential for in vitro organogenesis in respect to shoot elongation and adventitious rooting ability, despite noticeable fluctuations during time course that might be due to endogenous rhythm effects (Champagnat et al. 1986). The results support the hypothesis that in trees, the intensity of the maturation process is susceptible to vary according to an intra-individual zonation, which generally increases from the bottom to the top (Bonga 1982). Similar trends were observed by Sanchez and Vieitez (1991) with regard to in vitro performance of basal and crown shoots in mature chestnut. The morphological and organogenic differences pointed out in our study were shown to have been 

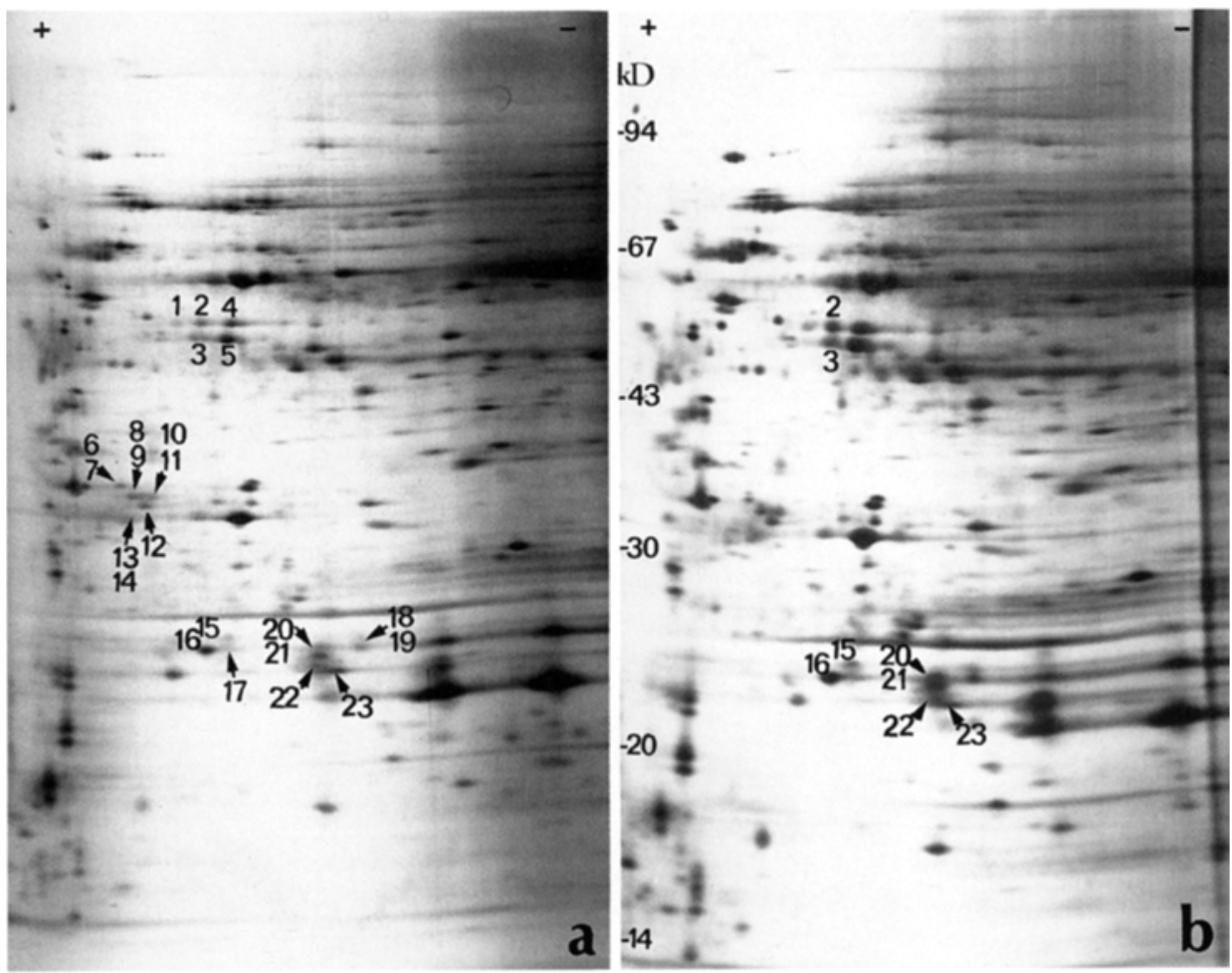

Fig. 2. Silver-stained two-dimensional gel of microsomal proteins extracted from microcuttings originated from the crown (a) and from the base (b) of a 90-year-old Sequoia sempervirens. In a, the arrows and the corresponding numbers indicate the quantitative differences of proteins with the basal origin. Eight of these 23 different proteins, significantly in higher abundance in the microcuttings originated from the base, are indicated in $\mathbf{b}$ maintained for 2 years in the experimental in vitro culture conditions. The persistence of this phenomenon, which was referred to as topophysis by Dodd and Power (1988), accounts for the intra-clonal variability so frequently noticed when attempting to clone mature trees.

Studies have been carried out on the same species to ascertain whether it is possible to reverse the phase change phenomenon, especially by subculturing in vitro the explants on cytokinin-enriched media (Fouret et al. 1986). This accounted for the positive effect of exogenous cytokinins to revert, at least temporarily, some mature traits, and is consistent with the hypothesis that the basal part of trees remains more juvenile due to natural root-produced cytokinins (Van Staden and Harty 1988). However, the fact that the presumed rejuvenation did not persist outside of its special experimental environment (Fouret 1987) illustrated once more the basic determinism of phase change.

The topophysis aspects observed were found to be associated with modifications of the microsomal protein fraction for which some polypeptides were found to be more abundant in stump shoot tissues that were presumably more juvenile. In Sequoiadendron giganteum, the rejuvenated line as well as the juvenile control also exhibited higher overall polypeptide concentrations than the original mature material, which was much less responsive for organogenesis (Monteuuis 1988). The prevailing trend emerging from the various but still quite limited investigations carried out in this field so far is that phase change involves both quantitative and qualitative changes, in terms of presence or absence of polypeptides, in protein contents (Huang et al. 1992), with a specific protein for the mature Citrus (Snowball et al. 1991), or with a greater number of spots in the more juvenile material (Bon and Monteuuis 1991). Special care has to be taken when ex- amining grafted material, as shown by Bon and Monteuuis (1987) working on shoots from grafted meristems collected from a 100-year-old giant sequoia, and who observed additional polypeptides, especially acidic ones, and some more abundant spots in the scions exhibiting mature traits as compared to the temporary morphologically rejuvenated ones. As hypothesized by Huang et al. (1992) grafting may involve the transfer of small molecules from the rootstock that might interfere with the scion peptides. In $S$. giganteum, the fact that specific immunoblotting against "J16" polypeptide revealed a second band only in tissue extracts from meristem grafts (Bon 1988b) tends to support this hypothesis.

Among the 23 microsomal proteins which appeared to be more abundantly synthesized in the material from the base, the results obtained so far, however, do not allow the identification of any of them to distinguish reliably between the two "topoclones", as was done with the so-called "J16" to differentiate between the juvenile and the mature status in $S$. giganteum whatever the environmental conditions (Bon 1988b). Also further investigations carried out to consider separately the total and the soluble protein fractions failed to establish any significant difference between the two origins. All these protein fractions were shown to be influenced too much by the physiological status which fluctuates greatly during the time course for each plant material origin, as illustrated by the reported variations of organogenic capacity. This is the reason why emphasis was given to the microsomal fraction, shown to be less affected by uncontrolled fluctuations of physiological status, and hence more reliable in terms of phase change indicators. Additional experiments are needed, however, to obtain a better evaluation of the date interaction on the microsomal protein patterns. Fluctuating physiological status is indeed a 
disturbing parameter which needs to be fully taken into consideration when investigating phase change in trees (Monteuuis and Bon 1986), even for plant material from the same genotype.

Lastly, the importance of carring out basic biochemical and molecular studies of phase change on plant material from the same genotype in order to avoid distorting genotypic interactions has to be emphasized. In that respect, Sequoia sempervirens with the coexistence within the same individual of juvenile and mature forms constitutes a good model to further our knowledge about the epigenetic basis of phase change.

Acknowledgements. The authors are grateful to the AFOCEL Laboratory of Biometrics for the statistical treatment of the data.

\section{References}

Bon MC (1988a) Nucleotide status and protein synthesis in vivo in the apices of juvenile and mature Sequoiadendron giganteum during budbreak. Physiol Plant 72: 796-800

Bon MC (1988 b) J16: an apex protein associated with juvenility of Sequoiadendron giganteum. Tree Physiol 4: 381-387

Bon MC (1989) A two-dimensional electrophoresis procedure for single meristems of different forest species. Electrophoresis 10 : $530-532$

Bon MC, Monteuuis O (1987) Application de la technique micro 2D PAGE au microgreffage de Sequoiadendron giganteum Buchholz. C R Acad Sci 305: 667-670

Bon MC, Monteuuis O (1991) Rejuvenation of a 100-year-old Sequoiadendron giganteum through in vitro meristem culture. II. Biochemical arguments. Physiol Plant 81: 116-120

Bonga JM (1982) Vegetative propagation in relation to juvenility, maturity and rejuvenation. In: Bonga JM, Durzan DJ (eds) Tissue culture in forestry. Martinus Nijhoff/Junk, The Hague, pp 387-412

Boulay M (1977) Multiplication rapide du Sequoia sempervirens en culture in vitro. Ann AFOCEL 1977: 37-66

Bradford MM (1976) A rapid and sensitive method for the quantitation of microgram quantities of protein using the principle of proteindye binding. Anal Biochem 72: 248-254

Brink RA (1962) Phase change in higher plants and somatic cell heredity. Q Rev Biol 37: 1-22

Champagnat P, Barnola P, Lavarenne S (1986) Quelques modalités de la croissance rythmique endogène des tiges chez les végétaux ligneux. In: Edelin $C$ (ed) Naturalia monspeliensa, Colloque international de l'arbre 1985, Montpellier, pp 279-302

Dodd RS, Power AB (1988) Clarification of the term topophysis. Silvae Gen 37: 14-15

Fortanier EJ, Jonkers H (1976) Juvenility and maturity of plants influenced by their ontogenetical and physiological ageing. Acta Hort 56: $37-44$
Fouret Y (1987) Etude in vitro du rajeunissement préalable à la micropropagation chez Sequoia sempervirens E. Recherche de marqueurs morphologiques, physiologiques et biochimiques. $\mathrm{PhD}$ thesis, University $\mathbf{P}$ et $\mathrm{M}$ Curie, Paris 6

Fouret Y, Arnaud Y, Larrieu C, Miginiac E (1986) Sequoia sempervirens as an in vitro rejuvenation model. $\mathrm{N} Z \mathrm{Z}$ J For Sci 16: $319-327$

Franclet A (1985) Rejuvenation: theory and practical experiences in clonal sylviculture. In: Zsuffa L, Rauter RM, Yeatman CW (eds) Clonal forestry: its impact on tree improvement and our future forests. Proc XIX meeting of the Canadian Tree Improvement Association, Toronto 1983, vol 2. Canadian Forestry Service, Ontario, pp 96-134

Fukasawa H (1966) Disc electrophoresis of proteins from juvenile and adult specimens of ivy. Nature 212: 516-517

Granier F, Vienne D de (1986) Silver staining of protein: standardized procedures for $2 \mathrm{D}$ gels bound to polyester sheets. Anal Biochem 155: $45-50$

Hackett WP (1983) Phase change and intra-clonal variability. Hort Sci 18: $12-16$

Hackett WP (1985) Juvenility, maturation and rejuvenation in woody plants. Hort Rev 7: 109-155

Huang LC, Lius S, Huang BL, Murashige T, Mahdi EFM, Van Gundy R (1992) Rejuvenation of Sequoia sempervirens by repeated grafting of shoot tips onto juvenile rootstocks in vitro. Plant Physiol 98: $166-173$

Monteuuis O (1988) Aspects du clonage de séquoias géants ( $S e$ quoiadendron giganteum B) jeunes et âgés. PhD Thesis, University Blaise Pascal, Clermont-Ferrand

Monteuuis O, Bon MC (1986) Microbouturage du séquoia géant. Ann AFOCEL 1985: 49-87

Sanchez MC, Vieitez AM (1991) In vitro morphogenetic competence of basal sprouts and crown branches of mature chestnut. Tree Physiol 8: $59-70$

SAS (1987) SAS/STAT guide for personal computers, version 6. SAS Institute, Cary, N. C.

Snowball AM, Zeman AM, Tchan YT, Mullins MG, Goodwin PB (1991) Phase change in Citrus: immunologically detectable differences between juvenile and mature plants. Aust J Plant Physiol 18: $385-396$

Struve DK, McKeand SE (1990) Growth and development of eastern white pine rooted cuttings compared with seedlings through 8 years of age. Can J For Res 20: 365-368

Van Staden J, Harty AR (1988) Cytokinins and adventitious root formation. In: Davis TM, Haissig BE, Sankhla N (eds) Adventitious root formation in cuttings. Dioscorides, Portland, pp 185-201

Verschoore-Martouzet B (1985) Etude de la variation topophysique au cours du clonage de Sequoia sempervirens (Endlicher). $\mathrm{PhD}$ thesis, University $\mathbf{P}$ et $\mathrm{M}$ Curie, Paris 6

Wareing PF (1987) Phase change and vegetative propagation. In: Abbott AJ, Atkin RK (eds) Improving vegetatively propagated crops. Academic Press, London, pp 263-270 